\title{
Factors Associated With Self-reported and Medically Diagnosed Urinary Incontinence Among Community-Dwelling Older Women In Korea
}

\author{
Jeongok Park ${ }^{1}$, Gwi-Ryung Son Hong², Wonhee Yang ${ }^{3}$ \\ ${ }^{1}$ College of Nursing, Yonsei University, Seoul, Korea \\ ${ }^{2}$ College of Nursing, Hanyang University, Seoul, Korea \\ ${ }^{3}$ Biostatistics, UNC Gillings School of Global Public Health, University of North Carolina at Chapel Hill, Chapel Hill, NC, USA
}

\begin{abstract}
Purpose: The purpose of this study was to examine the prevalence of urinary incontinence (UI) in community-dwelling Korean women 60 years or older, and to identify factors associated with self-reported and medically diagnosed UI.

Methods: This study was a secondary analysis of data from the 2008 Actual Living Condition of the Elderly and Welfare Need Survey, which used a stratified two-stage cluster sampling method to select a representative sample of 8,961 elderly Korean women. Results: Of the 8,961 women in this study, 579 (6.5\%) had self-reported UI, and 209 (2.3\%) were medically diagnosed with UI. As patient age and exercise ability of the upper extremities increased, risk for self-reported UI decreased (odds ratio [OR], 0.98 ; 95\% confidence interval [CI], 0.96-0.99; OR, 0.99; 95\% CI, 0.98-0.99, respectively). In contrast, as the number of limited instrumental activities of daily living (IADL) increased, the risk for self-reported UI increased (OR, 1.30; 95\% CI, 1.24-1.35). Overweight women were 1.94 times more likely to have self-reported UI compared to underweight women. Women with a history of stroke or asthma were more likely to have self-reported UI compared to women with no history. Also, women who reported being in good health were less likely to have UI, compared to women who reported being in poor health $(\mathrm{OR}, 0.47 ; 95 \% \mathrm{CI}$, 0.31-0.70). Medically diagnosed UI was negatively associated with the number of limited IADL and exercise ability scores for the lower extremities (OR, 0.86; $95 \% \mathrm{CI}, 0.80-0.92$; OR, 0.98 ; $95 \% \mathrm{CI}, 0.97-0.99$, respectively). In contrast, as the exercise ability score for the upper extremities increased, so did the risk for medically diagnosed UI (OR, 1.02; 95\% CI, 1.01-1.03).

Conclusions: An interventional program for home visit health services is needed for incontinent women who are highly dependent on others for IADL.
\end{abstract}

Keywords: Urinary Incontinence; Women; Prevalence

- Grant Support: This study was supported by the internal research fund at Hanyang University in 2013-2014.

- Research Ethics: This study was approved by the Institutional Review Board of Hanyang University for secondary data analysis (IRB No. HY15-085-1).

- Conflict of Interest: No potential conflict of interest relevant to this article was reported.

\section{INTRODUCTION}

Urinary incontinence, defined by the International Urogynecology Association and the International Continence Society joint report [1] as "complaint of involuntary loss of urine," is a common condition in older women. According to populationbased studies, the prevalence of UI in Korean women 60 years or older ranges from $10.3 \%-39.6 \%$ [2]; in Western countries,

Corresponding author: Gwi-Ryung Son Hong (D) http://orcid.org/0000-0001-7460-4972 College of Nursing, Hanyang University, 222 Wangsimni-ro, Seongdong-gu, Seoul 133-791, Korea

E-mail: grson@hanyang.ac.kr / Tel: +82-2-2220-0701 / Fax: +82-2-2295-2074 Submitted: : June 5, 2015 / Accepted after revision: June 22, 2015 
the prevalence ranges from $24 \%-41 \%$ in women aged 65 years or older $[3,4]$. Considering the high UI prevalence in Korea, the percentage of women who receive a medical diagnosis of UI or who seek treatment for it is low. In Western countries, $12 \%-$ $38 \%$ [5-7] of incontinent women were reported to seek a medical diagnosis for their symptoms; however, only 7.5\% of Korean women did so [8].

In the literature, body mass index (BMI) [3,9]; self-reported health status [3]; musculoskeletal problems, such as lower back disorders, grip strength, or walking speed $[9,10]$; and a history of falling [3,9], were associated with UI among older women. Duration of UI; history of a notable accident; a low quality of life; embarrassment associated with talking about UI; and comorbidities, such as arthritis, diabetes mellitus (DM), hypertension, or heart disease, were significantly associated with a medical diagnosis of UI $[5,6]$.

There are several differences in the factors associated with selfreported UI and medically diagnosed UI, according to literature from other countries. Little has been reported, however, on UI epidemiology among older Korean women. To provide appropriate interventions for older women with UI, it is important to learn more about their common risk factors. With that in mind, we investigated the prevalence of UI and identified factors associated with self-reported and medically diagnosed UI among community-dwelling Korean women aged 60 years or older.

\section{MATERIALS AND METHODS}

\section{Study Subjects}

The Actual Living Condition of the Elderly and Welfare Need Survey was conducted by the Korean Ministry of Health and Welfare. This survey began in 2008, and data collection is repeated every 3 years in order to provide longitudinal population-based information about the living conditions and welfare needs of older Koreans. The 2008 dataset, rather than later versions, was used for this study, because it is the only one to include information about UI. This survey used a stratified twostage cluster sampling process to select a representative sample of the elderly Korean population. A total of 15,146 individuals aged 60 years or older (male, 6,185; female, 8,961) were interviewed for the 2008 dataset, but we only selected the female participants $(n=8,961)$ for this study. The Institutional Review Board of Hanyang University approved our protocol for secondary data analysis (IRB No. HY-15-085-1).

\section{Measurements \\ Demographics and comorbidities}

Demographic data analyzed in this study were age, BMI (underweight, normal, or overweight), educational level (no education, elementary school, or middle school or higher), and place of residence (major metropolis, medium-size city, rural town). For self-reported health status, we aggregated data so that responses such as "very healthy" and "healthy" were categorized as "good"; a response of "average" was categorized as "fair"; "not healthy" and "not very healthy" were categorized as "poor." Past and current health problems, including hypertension, stroke, $\mathrm{DM}$, asthma, depression, and history of falls, were also included in our analyses.

\section{Definition of self-reported UI and medical diagnosis of UI}

Women were defined as having self-reported UI if they answered "yes" to the question, "Do you have UI?" Women were defined as having been medically diagnosed with UI if they responded "yes" to both of the following questions: "Do you have UI?" and "Was your UI diagnosed by a doctor?"

\section{Depression}

We used a shortened version of the geriatric depression scale (GDS) developed by Yesavage and Sheikh [11], and translated into Korean by Cho et al. [12], in order to evaluate depression for this study. The shortened version of the GDS consists of 15 yes (1) or no (0) questions. The overall possible score ranged from 0 to 15; the higher the score, the more severe the depression. We categorized women having a score of $0-7$ as normal, while women having a score $\geq 8$ were categorized as having depression.

\section{Instrumental activities of daily living}

A total of 10 items (ability to care for the body, use the telephone, shopping, prepare food, do housekeeping, go out of the house without transportation, do laundry, manage their own mode of transportation, take responsibility for medications, and handle finances) was evaluated to estimate instrumental activities of daily living (IADL) score. Each woman's total number of limited IADL was used for our analyses. The total scores ranged from $0-10$, and a lower score indicated a higher level of independence.

\section{Cognitive status}

The Mini-Mental Status Examination in the Korean version of 
the Consortium to Establish a Registry for Alzheimer's Disease Assessment Packet (MMSE-KC) was used to evaluate cognitive status. The total possible score ranged from $0-30$, where a high score indicated high cognitive ability.

\section{Exercise ability of the upper extremities}

Exercise ability of the upper extremities was assessed with two questions: "How difficult is it to stretch your arms toward an object that is placed above your head?" and "How difficult is it to lift or move an object that weighs about $8 \mathrm{~kg}$ ?" The response format for these questions was "cannot do it (0)," "very difficult (1)," "somewhat difficult (2)," and "not difficult (3)." Each woman's average score for these two questions was transformed to a score on a 100-point scale. Therefore, the total score ranged from $0-100$, and a higher score indicated a higher level of exercise ability of the upper extremities.

\section{Exercise ability of the lower extremities}

Exercise ability of the lower extremities was assessed by three questions: "How difficult is it to run $400 \mathrm{~m}$ ?" "How difficult is it to climb 10 steps without stopping?" and "How difficult is it to bend forward, squat down, or kneel down?” The response format for these questions was the same as for the upper extremities. Each average score for these three questions was transformed to a 100-point scale, so the total score ranged from $0-100$, and a higher score indicated a higher level of exercise ability.

\section{Statistical Analyses}

Statistical analyses were performed using SAS 9.4 (SAS Institute Inc., Cary, NC, USA). For general characteristics, descriptive statistics were performed. To determine the multicollinearity among independent variables, the variance inflation factor, Fisher exact test, and a correlation test were used. Logistic regressions were used for both univariate and multivariate analyses. To construct a multivariate model, logistic regression with forward selection was performed. All P-values $\leq 0.05$, for both univariate and multivariate logistic regressions, were considered to be statistically significant.

\section{RESULTS}

\section{General Characteristics}

Table 1 describes the characteristics of all study women and women with self-reported and medically diagnosed UI. Of the 8,961 women studied, 579 (6.5\%) had self-reported UI. Among the incontinent women, only 209 (2.3\%) were medically diagnosed. The average age of the entire study sample was 71.2 years (standard deviation $[\mathrm{SD}], \pm 7.2$ ). The percentage of overweight women was $36.4 \%$ among the total sample, and $42.6 \%$ among the incontinent women. Approximately $44 \%$ of the women had no education, and $40 \%$ of the women had only an elementary education. The majority of incontinent women (83.7\%) reported their health status as poor. Among all the women in our sample, 48\% had hypertension, $16.4 \%$ had DM, 33.2\% had depression, and $18.9 \%$ had a history of falling. In contrast, among the incontinent women, $54.7 \%$ had hypertension, $21.9 \%$ had DM, 52\% had depression, and $29.7 \%$ had a history of falls. Women with a history of stroke or asthma made up only $5.3 \%$ and $3 \%$ of the sample population, respectively. Regarding daily function, the average number of limited IADL and the average scores on the MMSE-KC in all study women were $1.0(\mathrm{SD}, \pm 2.2)$ and 22.4 (SD, \pm 4.9 ), respectively, while those scores among the incontinent women were $3.8(\mathrm{SD}, \pm 4.0)$ and $19.4(\mathrm{SD}, \pm 7.1$ ). The average scores for exercise ability of the upper and lower extremities among the total sample of women were $68.4(\mathrm{SD}, \pm 28.9)$ and 50.4 (SD, \pm 28.0 ), respectively. Those scores for the incontinent women were 46.3 (SD, \pm 33.8 ) and $32.9(\mathrm{SD}, \pm 28.3$ ). With the exception of education level, all analyzed variables were statistically significant in comparison between total sample and women with self-reported UI (P-values ranged from 0.003 to $<0.001$ ).

\section{Factors Associated With Self-reported UI}

In univariate logistic regression analyses, age, BMI, place of residence, self-reported health status, hypertension, history of stroke, DM, asthma, depression, history of falling, IADL, cognitive function, and exercise abilities of the upper and lower extremities were significantly associated with self-reported UI (Table 2). Multivariate logistic regression showed that age ( $\mathrm{P}=0.009)$, BMI $(\mathrm{P}=0.001)$, place of residence $(\mathrm{P}<0.001)$, selfreported health status $(\mathrm{P}=0.001)$, history of stroke $(\mathrm{P}=0.045)$, asthma $(\mathrm{P}=0.031)$, IADL $(\mathrm{P}<0.001)$, and exercise ability of the upper extremities $(\mathrm{P}<0.001)$ were independently associated with self-reported UI. In detail, as age and exercise ability of the upper extremities score increased, ORs for UI decreased (OR, 0.98; 95\% CI, 0.96-0.99; OR, 0.99; 95\% CI, 0.98-0.99, respectively). On the contrary, as the number of limited IADL increased, OR for UI increased (OR, 1.30; 95\% CI, 1.24-1.35). Women who were overweight were 1.94 times more likely to have UI compared to underweight women (OR, 1.94; 95\% CI, 1.16-3.24). Similarly, women with a history of stroke or asthma 
Table 1. General characteristics of the sample population

\begin{tabular}{|c|c|c|c|c|c|}
\hline \multirow[b]{2}{*}{ Variable } & \multirow{2}{*}{$\begin{array}{c}\text { Total } \\
(\mathrm{n}=8,961)\end{array}$} & \multicolumn{2}{|c|}{ Incontinent women } & \multirow[b]{2}{*}{ t or chi-square } & \multirow[b]{2}{*}{ P-value ${ }^{\mathrm{b})}$} \\
\hline & & $\begin{array}{l}\text { Self-reported } \\
\quad(n=579)\end{array}$ & $\begin{array}{l}\text { Medically diagnosed } \\
\quad(\mathrm{n}=209)^{\mathrm{a})}\end{array}$ & & \\
\hline Age (yr) & $71.20 \pm 7.23(60-104)$ & $73.61 \pm 8.24(60-104)$ & $72.16 \pm 7.21(60-100)$ & -8.33 & $<0.001$ \\
\hline $\begin{array}{l}\left.\text { Body mass index }\left(\mathrm{kg} / \mathrm{m}^{2}\right)^{\mathrm{c}}\right) \\
\text { Underweight }(<18.5) \\
\text { Normal }(\geq 18.5 \text { or }<25) \\
\geq \text { Overweight }(\geq 25)\end{array}$ & $\begin{array}{c}399 / 8,331(4.8) \\
4,898 / 8,331(58.8) \\
3,034 / 8,331(36.4)\end{array}$ & $\begin{array}{c}20 / 451(4.4) \\
239 / 451(53.0) \\
192 / 451(42.6)\end{array}$ & $\begin{array}{c}8 / 185(4.3) \\
92 / 185(49.7) \\
85 / 185(46.0)\end{array}$ & 7.81 & 0.02 \\
\hline $\begin{array}{l}\text { Place of residence } \\
\text { Metropolis (gu) } \\
\text { Medium-size city (dong) } \\
\text { Rural town (eup/myeon) }\end{array}$ & $\begin{array}{l}2,728(30.4) \\
2,913(32.5) \\
3,320(37.0)\end{array}$ & $\begin{array}{l}211(36.4) \\
182(31.4) \\
186(32.1)\end{array}$ & $\begin{array}{l}78(37.3) \\
66(31.6) \\
65(31.1)\end{array}$ & 11.59 & 0.003 \\
\hline $\begin{array}{l}\text { Educational level } \\
\text { No education } \\
\text { Elementary school } \\
\geq \text { Middle school }\end{array}$ & $\begin{array}{l}3,907(43.6) \\
3,562(39.8) \\
1,492(16.7)\end{array}$ & $\begin{array}{r}268(46.3) \\
221(38.2) \\
90(15.5)\end{array}$ & $\begin{array}{l}75(35.9) \\
88(42.1) \\
46(22.0)\end{array}$ & 1.87 & 0.393 \\
\hline $\begin{array}{l}\text { Self-reported health status } \\
\text { Poor } \\
\text { Fair } \\
\text { Good }\end{array}$ & $\begin{array}{l}6,025 / 8,943(67.4) \\
1,325 / 8,943(14.8) \\
1,593 / 8,943(17.8)\end{array}$ & $\begin{array}{c}478 / 571(83.7) \\
59 / 571(10.3) \\
34 / 571(6.0)\end{array}$ & $\begin{array}{c}171(81.8) \\
23(11.0) \\
15(7.2)\end{array}$ & 80.60 & $<0.001$ \\
\hline $\begin{array}{l}\text { Past \& current health problems }{ }^{\mathrm{f}} \text { ) } \\
\text { Hypertension } \\
\text { Stroke } \\
\text { Diabetes mellitus } \\
\text { Asthma } \\
\text { Depression } \\
\text { Falls }\end{array}$ & $\begin{array}{c}4,298(48.0) \\
475(5.3) \\
1,466(16.4) \\
268(3.0) \\
2,978(33.2) \\
1,695(18.9)\end{array}$ & $\begin{array}{c}317(54.7) \\
88(15.2) \\
127(21.9) \\
30(5.2) \\
301(52.0) \\
172(29.7)\end{array}$ & $\begin{array}{l}190(51.4) \\
60(16.2) \\
76(20.5) \\
14(3.8) \\
204(58.3) \\
116(31.4)\end{array}$ & $\begin{array}{r}11.42 \\
120.81 \\
14.06 \\
10.24 \\
115.14 \\
47.00\end{array}$ & $\begin{array}{r}<0.001 \\
<0.001 \\
<0.001 \\
0.001 \\
<0.001 \\
<0.001\end{array}$ \\
\hline $\begin{array}{l}\text { Functional ability } \\
\text { IADL } \\
\text { Cognitive status }^{\mathrm{h})}\end{array}$ & $\begin{array}{c}1.02 \pm 2.20(0-0) \\
22.36 \pm 4.87(0-30)\end{array}$ & $\begin{array}{r}3.80 \pm 3.99(0-10) \\
19.35 \pm 7.09(0-30)\end{array}$ & $\begin{array}{r}4.71 \pm 4.09(0-10) \\
17.99 \pm 7.52(0-30)\end{array}$ & $\begin{array}{r}-33.47 \\
15.16\end{array}$ & $\begin{array}{l}<0.001 \\
<0.001\end{array}$ \\
\hline $\begin{array}{l}\text { Physical strength } \\
\text { Exercise ability of upper extremities }{ }^{\mathrm{i})} \\
\text { Exercise ability of lower extremities }\end{array}$ & $\begin{array}{l}68.37 \pm 28.89(0-100) \\
50.44 \pm 27.97(0-100)\end{array}$ & $\begin{array}{l}46.27 \pm 33.80(0-100) \\
32.92 \pm 28.28(0-100)\end{array}$ & $\begin{array}{l}39.55 \pm 33.30(0-100) \\
29.66 \pm 28.31(0-100)\end{array}$ & $\begin{array}{l}19.06 \\
15.51\end{array}$ & $\begin{array}{l}<0.001 \\
<0.001\end{array}$ \\
\hline
\end{tabular}

Values are presented as mean \pm standard deviation (range) or number (\%).

IADL, instrumental activities of daily living; MMSE-KC, Mini-Mental Status Examination in the Korean version of the Consortium to Establish a Registry for Alzheimer's disease assessment packet.

${ }^{a}$ )Women with medically diagnosed urinary incontinence (UI) were included in women with self-reported UI. ${ }^{\text {b) }}$ The value of t or chi-square was resulted from comparison between total $(\mathrm{n}=8,961)$ and incontinent women $(\mathrm{n}=579)$. ${ }^{\mathrm{c}} 630$ missing in total group, 128 missing in self-reported UI group, 24 missing in medically diagnosed UI group. ${ }^{\text {d) }}$ Metropolis indicates Seoul, Busan, Daegu, Incheon, Gwangju, Daejeon, and Ulsan. ${ }^{\text {e) }} 18$ missing in total group, 8 missing in self-reported UI group. ${ }^{\mathrm{f}}$ Multiple responses. ${ }^{\mathrm{g}}{ }^{104}$ missing in total group. ${ }^{\text {h) }} 202$ missing in total group. ${ }^{\text {i) }} 69$ missing in total group. ${ }^{j} 121$ missing in total group.

were more likely to have UI, compared with women without these conditions (OR, 1.49; 95\% CI, 1.01-2.08; OR, 1.68; 95\% CI, 1.05-2.68, respectively). Women who reported good health were less likely to have UI compared to women who reported poor health (OR, 0.47; 95\% CI, 0.31-0.70).

\section{Factors Associated With Medically Diagnosed UI}

In univariate logistic regression analyses, age, education level, hypertension, asthma, depression, IADL, cognitive status, and exercise abilities of the upper and lower extremities were significantly associated with medically diagnosed UI (Table 3). In multivariate logistic regression, only IADL and exercise abilities of the upper and lower extremities were independently associated with medically diagnosed UI. In detail, as the number of limited IADL and the score for exercise ability of the lower extremities increased, risk for medically diagnosed UI decreased 
Table 2. Factors associated with self-reported urinary incontinence among older women

\begin{tabular}{|c|c|c|c|c|}
\hline \multirow{2}{*}{ Variable } & \multicolumn{2}{|c|}{ Univariate } & \multicolumn{2}{|c|}{ Multivariate } \\
\hline & OR $(95 \% \mathrm{CI})$ & $\mathrm{P}$-value & OR $(95 \%$ CI $)$ & P-value \\
\hline Age (yr) & $1.05(1.04-1.06)$ & 0.001 & $0.98(0.96-0.99)$ & 0.009 \\
\hline $\begin{array}{l}\text { Body mass index }\left(\mathrm{kg} / \mathrm{m}^{2}\right) \\
\text { Underweight }(<18.5) \\
\text { Normal }(\geq 18.5,<25) \\
\geq \text { Overweight }(\geq 25)\end{array}$ & $\begin{array}{c}\text { Reference } \\
0.97(0.61-1.55) \\
1.28(0.80-2.05)\end{array}$ & $\begin{array}{l}0.021 \\
0.906 \\
0.306\end{array}$ & $\begin{array}{c}\text { Reference } \\
1.39(0.84-2.31) \\
1.94(1.16-3.24)\end{array}$ & $\begin{array}{l}0.001 \\
0.144 \\
0.006\end{array}$ \\
\hline $\begin{array}{l}\text { Educational level } \\
\text { No education } \\
\text { Elementary school } \\
\geq \text { Middle school }\end{array}$ & $\begin{array}{c}\text { Reference } \\
0.90(0.75-1.08) \\
0.87(0.68-1.12)\end{array}$ & $\begin{array}{l}0.393 \\
0.253 \\
0.275\end{array}$ & & \\
\hline $\begin{array}{l}\text { Place of residence } \\
\text { Metropolis (gu) } \\
\text { Medium-size city (dong) } \\
\text { Rural town (eup/myeon) }\end{array}$ & $\begin{array}{l}1.41(1.15-1.73) \\
1.12(0.91-1.39) \\
\text { Reference }\end{array}$ & $\begin{array}{l}0.003 \\
0.001 \\
0.281\end{array}$ & $\begin{array}{l}1.71(1.34-2.19) \\
1.12(0.87-1.45) \\
\text { Reference }\end{array}$ & $\begin{array}{r}<0.001 \\
0.001 \\
0.655\end{array}$ \\
\hline $\begin{array}{l}\text { Self-reported health status } \\
\text { Poor } \\
\text { Fair } \\
\text { Good }\end{array}$ & $\begin{array}{c}\text { Reference } \\
0.54(0.41-0.71) \\
0.25(0.18-0.36)\end{array}$ & $\begin{array}{l}<0.001 \\
<0.001 \\
<0.001\end{array}$ & $\begin{array}{c}\text { Reference } \\
1.04(0.76-1.40) \\
0.47(0.31-0.70)\end{array}$ & $\begin{array}{r}0.001 \\
0.703 \\
<0.001\end{array}$ \\
\hline $\begin{array}{l}\text { Past \& current health problems } \\
\text { Hypertension } \\
\text { Stroke } \\
\text { Diabetes mellitus } \\
\text { Asthma } \\
\text { Depression } \\
\text { Falls }\end{array}$ & $\begin{array}{l}1.34(1.13-1.58) \\
3.70(2.89-4.75) \\
1.48(1.20-1.82) \\
1.87(1.27-2.76) \\
2.52(2.12-3.00) \\
1.90(1.58-2.29)\end{array}$ & $\begin{array}{r}0.001 \\
<0.001 \\
<0.001 \\
0.002 \\
<0.001 \\
<0.001\end{array}$ & $\begin{array}{l}1.49(1.01-2.08) \\
1.68(1.05-2.68)\end{array}$ & $\begin{array}{l}0.045 \\
0.031\end{array}$ \\
\hline $\begin{array}{l}\text { Functional ability } \\
\text { IADL } \\
\text { Cognitive status }^{\text {b) }}\end{array}$ & $\begin{array}{l}1.40(1.37-1.44) \\
0.90(0.88-0.91)\end{array}$ & $\begin{array}{l}<0.001 \\
<0.001\end{array}$ & $1.30(1.24-1.35)$ & $<0.001$ \\
\hline $\begin{array}{l}\text { Physical strength } \\
\text { Exercise ability of upper Extremities } \\
\text { Exercise ability of lower Extremities }\end{array}$ & $\begin{array}{l}0.98(0.97-0.98) \\
0.98(0.97-0.98)\end{array}$ & $\begin{array}{l}<0.001 \\
<0.001\end{array}$ & $0.99(0.98-0.99)$ & $<0.001$ \\
\hline
\end{tabular}

OR, odds ratio; CI, confidence interval; IADL, instrumental activities of daily living.

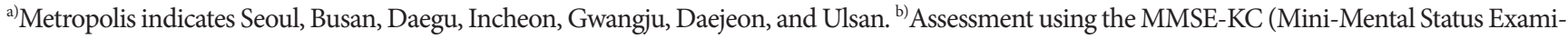
nation in the Korean version of the Consortium to Establish a Registry for Alzheimer's disease assessment packet).

(OR, 0.86; 95\% CI, 0.80-0.92; OR, 0.98; 95\% CI, 0.97-0.99, respectively). In contrast, as the score of exercise ability of the upper extremities increased, risk for medically diagnosed UI increased (OR, 1.02; 95\% CI, 1.01-1.03).

\section{DISCUSSION}

This study examined the prevalence of UI and identified factors associated with self-reported and medically diagnosed UI among community-dwelling Korean women aged 60 years or older. The prevalence of self-reported UI in our study (6.5\%) was lower than that of previous studies of Korean women $\geq 60$ years old $[2,8]$, which ranged from $10.3 \%$ to $39.6 \%$. This difference may be because we used different data to define UI. Specifically, Lee et al. [2] investigated examples of UI with statements such as: "Sometimes these incidents occur when coughing, sneezing, laughing, or during physical activity, or other occasions that are associated with a feeling of pressure on the bladder." They also asked: "During the last 30 days, did you experience any of these symptoms?" It is possible that women who participated in Lee et al. [2]'s study understood the questions and answered them correctly. In our study, however, questions such as "Do you have UI?" might have been confusing, because the subjects might not understand the term "UI." Thus, 
Table 3. Factors associated with medically diagnosed urinary incontinence among incontinent women

\begin{tabular}{|c|c|c|c|c|}
\hline \multirow{2}{*}{ Variable } & \multicolumn{2}{|c|}{ Univariate } & \multicolumn{2}{|c|}{ Multivariate } \\
\hline & OR (95\% CI) & $\mathrm{P}$-value & OR (95\% CI) & P-value \\
\hline Age (yr) & $0.97(0.95-0.99)$ & 0.002 & & \\
\hline $\begin{array}{l}\text { Body mass index }\left(\mathrm{kg} / \mathrm{m}^{2}\right) \\
\text { Underweight }(<18.5) \\
\text { Normal }(\geq 18.5,<25) \\
\text { Overweight }(\geq 25)\end{array}$ & $\begin{array}{c}\text { Reference } \\
0.94(0.37-2.38) \\
1.19(0.47-3.05)\end{array}$ & $\begin{array}{l}0.478 \\
0.894 \\
0.714\end{array}$ & & \\
\hline $\begin{array}{l}\text { Educational level } \\
\text { No education } \\
\text { Elementary school } \\
\geq \text { Middle school diploma }\end{array}$ & $\begin{array}{c}\text { Reference } \\
1.70(1.65-4.40) \\
2.69(1.65-2.49)\end{array}$ & $\begin{array}{r}<0.001 \\
0.006 \\
<0.001\end{array}$ & & \\
\hline $\begin{array}{l}\text { Place of residence } \\
\text { Metropolis (gu) } \\
\text { Medium-size city (dong) } \\
\text { Rural town (eup/myeon) }\end{array}$ & $\begin{array}{l}1.09(0.72-1.65) \\
1.06(0.69-1.62) \\
\text { Reference }\end{array}$ & $\begin{array}{l}0.915 \\
0.676 \\
0.792\end{array}$ & & \\
\hline $\begin{array}{l}\text { Self-reported health status } \\
\text { Poor } \\
\text { Fair } \\
\text { Good }\end{array}$ & $\begin{array}{c}\text { Reference } \\
1.15(0.67-2.00) \\
1.52(0.70-2.86)\end{array}$ & $\begin{array}{l}0.575 \\
0.629 \\
0.330\end{array}$ & & \\
\hline $\begin{array}{l}\text { Past \& current health problems } \\
\text { Hypertension } \\
\text { Stroke } \\
\text { Diabetes mellitus } \\
\text { Asthma } \\
\text { Depression } \\
\text { Falls }\end{array}$ & $\begin{array}{l}1.47(1.04-2.07) \\
0.80(0.49-1.30) \\
1.25(0.83-1.87) \\
2.11(1.01-4.41) \\
0.66(0.46-0.93) \\
0.80(0.55-1.17)\end{array}$ & $\begin{array}{l}0.029 \\
0.365 \\
0.281 \\
0.048 \\
0.017 \\
0.250\end{array}$ & & \\
\hline $\begin{array}{l}\text { Functional ability } \\
\text { IADL } \\
\text { Cognitive status }^{\text {b) }}\end{array}$ & $\begin{array}{l}0.84(0.80-0.88) \\
1.09(1.06-1.23)\end{array}$ & $\begin{array}{l}<0.001 \\
<0.001\end{array}$ & $0.86(0.80-0.92)$ & $<0.001$ \\
\hline $\begin{array}{l}\text { Physical strength } \\
\text { Exercise ability of upper extremities } \\
\text { Exercise ability of lower extremities }\end{array}$ & $\begin{array}{l}1.02(1.01-1.02) \\
1.01(1.01-1.02)\end{array}$ & $\begin{array}{l}<0.001 \\
<0.001\end{array}$ & $\begin{array}{l}1.02(1.01-1.03) \\
0.98(0.97-0.99)\end{array}$ & $\begin{array}{r}<0.001 \\
0.003\end{array}$ \\
\hline
\end{tabular}

OR, odds ratio; CI, confidence interval; IADL, instrumental activities of daily living.

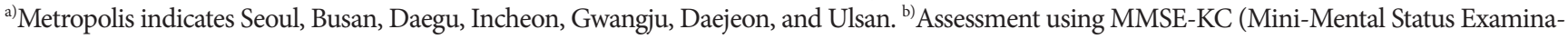
tion in the Korean version of the Consortium to Establish a Registry for Alzheimer's disease assessment packet).

they might not have answered correctly, leading to a problem of underreporting in our study. This may especially have been a problem in our sample, because approximately $44 \%$ of the women were categorized as having no education.

In this study, the prevalence of medically diagnosed UI was $2.3 \%$, and the rate of medically diagnosed UI $(n=209)$ among incontinent women ( $\mathrm{n}=579)$ was $36 \%$. The prevalence of medically diagnosed UI among Korean women aged 19 years or older was $11.1 \%$ [2], while the consultation rate for incontinent adult European women was 31\% [6]. This low rate of medical diagnosis among older Korean women could be explained by their consideration of UI as a part of normal age-related chang- es. Since little research has been conducted to examine the prevalence of medically diagnosed UI in exclusively older women, comparing these results with other studies is difficult, but necessitates further research.

In other studies, overweight women $[9,13,14]$ and those with poorer health status $[3,14]$ were significantly associated with self-reported UI, which is consistent with the results of the current study. A few studies have examined the association between age and UI exclusively among community-dwelling older women, and they all found that older age increased the risk of self-reported UI $[13,15]$. Interestingly, our study found the opposite association between age and self-reported UI. To explain 
this result, we conducted further analyses in which we found that there was a significant association between age and BMI. Specifically, average ages of underweight and overweight women were 75.1 years $(S D, \pm 8.0)$ and 69.8 years $(S D, \pm 6.5)$, respectively $(\mathrm{P}<0.001)$. Thus, in our study, younger age was associated with being overweight, which could play a role in the association between younger age and UI.

Regarding residential setting, women living in a large metropolitan city were more likely to have self-reported UI, compared to women living in a small town. We also found that there was a significant trend among places of residence and overweight $(\mathrm{P}<0.001)$, in that the proportion of overweight women is likely to increase as the size of residential place becomes larger (rural to metropolis). Women living in a rural town in Korea were more likely to be involved in farming, which requires heavy physical labor, leading to fewer problems with obesity.

We also found that women with a history of stroke or asthma were more likely to report UI compared to women without these conditions. UI is a common symptom after stroke, and the prevalence of poststroke incontinence is in the range of $17 \%-44 \%$ [16-18]. In contrast, conflicting evidence exists regarding the association between asthma and UI in women [1921], highlighting the need for more research in this area. Most women with a history of stroke or asthma have regular appointments with a healthcare provider regarding these problems, and their frequent/regular hospital visits offer more opportunities to seek medical treatment for their UI $[5,6]$.

Voiding-related abilities, including muscle strength of the upper and lower extremities, are critical to avoiding incontinence, especially because urinary frequency and urgency are prevalent among older women [2,22]. Associations between UI and functional conditions, such as walking speed, static balance, or knee pain among older women have been reported [3,9,23-25]. The current study found that self-reported UI was independently associated with a higher level of dependency for IADL, and a lower score of exercise ability of the upper extremities; however, exercise ability of the lower extremities was not an independent factor for self-reported UI.

This study also identified factors associated with medically diagnosed UI. While a higher level of dependency for IADL was associated with self-reported UI, it was negatively associated with medical diagnosis of UI. This indicates that physical independency is a critical factor that encourages older women to see a health care provider for UI. With regard to exercise abili- ties of the extremities, we found conflicting results. Medical diagnosis for UI was independently associated with high-level exercise ability of the upper extremities and low-level exercise ability of the lower extremities. It is possible that the chosen scores for these exercise abilities measured more than minimal physical ability, which is required for getting oneself to the hospital. That is, when women have lower scores for lower-extremity exercise ability, they might still have enough physical ability to travel to the hospital to seek treatment for UI; however, more studies are needed.

This study has a few limitations. First, since this was a secondary analysis using national-level data, potential risk factors for self-reported and medically diagnosed UI, such as parity, history of hysterectomy, type and severity of UI, and quality of life, were not included. In particular, prevalence and factors related to self-reported and medically diagnosed UI may differ, based on the types of UI in women. Second, this study used a cross-sectional design; thus, the causal relationship between UI and related factors could not be examined.

In conclusion, UI is a common health problem among older Korean women, and is independently associated with age, BMI, place of residence, self-reported health status, history of stroke, asthma, IADL, and exercise ability of the upper extremities. Incontinent women seeking a medical diagnosis for UI were significantly more likely to have higher independence for IADL. Our results suggest that development of an intervention program for UI based on home-visit health services is needed for incontinent women who are highly-dependent on others for IADL.

\section{REFERENCES}

1. Haylen BT, de Ridder D, Freeman RM, Swift SE, Berghmans B, Lee J, et al. An International Urogynecological Association (IUGA)/International Continence Society (ICS) joint report on the terminology for female pelvic floor dysfunction. Neurourol Urodyn 2010;29:4-20.

2. Lee KS, Sung HH, Na S, Choo MS. Prevalence of urinary incontinence in Korean women: results of a National Health Interview Survey. World J Urol 2008;26:179-85.

3. Bresee C, Dubina ED, Khan AA, Sevilla C, Grant D, Eilber KS, et al. Prevalence and correlates of urinary incontinence among older community-dwelling women. Female Pelvic Med Reconstr Surg 2014;20:328-33.

4. Goode PS, Burgio KL, Redden DT, Markland A, Richter HE, Saw- 
yer P, et al. Population based study of incidence and predictors of urinary incontinence in black and white older adults. J Urol 2008;179:1449-53.

5. Kinchen KS, Burgio K, Diokno AC, Fultz NH, Bump R, Obenchain R. Factors associated with women's decisions to seek treatment for urinary incontinence. J Womens Health (Larchmt) 2003;12:687-98.

6. O’Donnell M, Lose G, Sykes D, Voss S, Hunskaar S. Help-seeking behaviour and associated factors among women with urinary incontinence in France, Germany, Spain and the United Kingdom. Eur Urol 2005;47:385-92.

7. Cetinel B, Demirkesen O, Tarcan T, Yalcin O, Kocak T, Senocak M, et al. Hidden female urinary incontinence in urology and obstetrics and gynecology outpatient clinics in Turkey: what are the determinants of bothersome urinary incontinence and help-seeking behavior? Int Urogynecol J Pelvic Floor Dysfunct 2007;18:659-64.

8. Kwon CS, Lee JH. Prevalence, risk factors, quality of life, and health-care seeking behaviors of female urinary incontinence: results from the 4th Korean National Health and Nutrition Examination Survey VI (2007-2009). Int Neurourol J 2014;18:31-6.

9. Kim H, Yoshida H, Hu X, Saito K, Yoshida Y, Kim M, et al. Association between self-reported urinary incontinence and musculoskeletal conditions in community-dwelling elderly women: a crosssectional study. Neurourol Urodyn 2015;34:322-6.

10. Kim JS, Kim SY, Oh DW, Choi JD. Correlation between the severity of female urinary incontinence and concomitant morbidities: a multicenter cross-sectional clinical study. Int Neurourol J 2010;14:220-6.

11. Yesavage JA, Sheikh JI. Geriatric depression scale (GDS): recent evidence and development of a shorter version. Clin Gerontol 1986;5:165-73.

12. Cho MJ, Bae JN, Suh GH, Hahm BJ, Kim JK, Lee DW, et al. Validation of geriatric depression scale, Korean version (GDS) in the Assessment of DSM-III-R major depression. J Korean Neuropsychiatr Assoc 1999;38:48-63.

13. Tseng IJ, Chen YT, Chen MT, Kou HY, Tseng SF. Prevalence of urinary incontinence and intention to seek treatment in the elderly. J Formos Med Assoc 2000;99:753-8.

14. Reigota RB, Pedro AO, de Souza Santos Machado V, Costa-Paiva L, Pinto-Neto AM. Prevalence of urinary incontinence and its association with multimorbidity in women aged 50 years or older: a population-based study. Neurourol Urodyn 2014 Oct 30 [Epub]. http:// dx.doi.org/10.1002/nau.22679.

15. Hsu A, Conell-Price J, Stijacic Cenzer I, Eng C, Huang AJ, RiceTrumble $\mathrm{K}$, et al. Predictors of urinary incontinence in community-dwelling frail older adults with diabetes mellitus in a cross-sectional study. BMC Geriatr 2014;14:137.

16. Jørgensen L, Engstad T, Jacobsen BK. Self-reported urinary incontinence in noninstitutionalized long-term stroke survivors: a population-based study. Arch Phys Med Rehabil 2005;86:416-20.

17. Cai W, Wang J, Wang L, Wang J, Guo L. Prevalence and risk factors of urinary incontinence for post-stroke inpatients in Southern China. Neurourol Urodyn 2015;34:231-5.

18. Williams MP, Srikanth V, Bird M, Thrift AG. Urinary symptoms and natural history of urinary continence after first-ever stroke: a longitudinal population-based study. Age Ageing 2012;41:371-6.

19. Horng SS, Huang N, Wu SI, Fang YT, Chou YJ, Chou P. The epidemiology of urinary incontinence and it's influence on quality of life in Taiwanese middle-aged women. Neurourol Urodyn 2013;32:3716.

20. Correia S, Dinis P, Rolo F, Lunet N. Prevalence, treatment and known risk factors of urinary incontinence and overactive bladder in the non-institutionalized Portuguese population. Int Urogynecol J Pelvic Floor Dysfunct 2009;20:1481-9.

21. van Gerwen M, Schellevis F, Lagro-Janssen T. Comorbidities associated with urinary incontinence: a case-control study from the Second Dutch National Survey of General Practice. J Am Board Fam Med 2007;20:608-10.

22. Irwin DE, Milsom I, Hunskaar S, Reilly K, Kopp Z, Herschorn S, et al. Population-based survey of urinary incontinence, overactive bladder, and other lower urinary tract symptoms in five countries: results of the EPIC study. Eur Urol 2006;50:1306-14.

23. Jackson SL, Scholes D, Boyko EJ, Abraham L, Fihn SD. Predictors of urinary incontinence in a prospective cohort of postmenopausal women. Obstet Gynecol 2006;108:855-62.

24. Gasquet I, Tcherny-Lessenot S, Gaudebout P, Bosio Le Goux B, Klein P, Haab F. Influence of the severity of stress urinary incontinence on quality of life, health care seeking, and treatment: a national cross-sectional survey. Eur Urol 2006;50:818-25.

25. Fritel X, Lachal L, Cassou B, Fauconnier A, Dargent-Molina P. Mobility impairment is associated with urge but not stress urinary incontinence in community-dwelling older women: results from the Ossébo study. BJOG 2013;120:1566-72. 